\title{
Emotional Intelligence and Coronary Heart Disease: How Close Is the Link?
}

\author{
Evrydiki Kravvariti \\ Department of Hygiene and Epidemiology \\ University of Athens Medical School, Greece \\ Katerina Maridaki-Kassotaki (Corresponding author) \\ Department of Home Economics and Ecology, Harokopio University \\ 70, El. Venizelou str., 176 71, Athens, Greece \\ E-mail: kmaridaki@hua.gr \\ Eleftherios Kravvaritis \\ A' Cardiology Clinic, Athens Naval Hospital, Greece
}

\begin{abstract}
The present paper examines the relationship between coronary heart disease and emotional intelligence. Fifty six patients with coronary heart disease and equal number of controls who had no indications of heart disease participated in the study. Two self-report questionnaires which assess components of trait emotional intelligence such as emotion perception, emotion regulation, emotion expression and use of emotions were given to all subjects. As hypothesized, the results emerged from the study indicated that facets of trait emotional intelligence such as decreased ability to use and regulate emotions as well as frequency of negative expressiveness are associated with incidence of coronary heart disease. The discussion focuses on the role and applications of trait emotional intelligence in the clinical domain.
\end{abstract}

Keywords: Emotional intelligence, Coronary heart disease, Emotion expression, Emotion perception, Emotion regulation, Negative emotions

\section{Introduction}

Cardiac disease, presently the leading cause of death worldwide has been a cause of suffering for centuries (Sandison, 1967; Moodie, 1923). Speculations about the aetiology of heart disease date back to Hippocrates (Aschoff, 1933; Harris, 1973; Parry, 1799). In most cultures, negative affect and stressful situations exceeding an individual's ability to cope have been implicated in adverse cardiac events (Lewis, 2005). Modern researchers have long suspected that there could be a seed of truth in this anecdotal wisdom (Boshes, 1958; Cerný, Dolezalová, Pokorná, \& Jirák, 1975; Friedman \& Rosenman, 1964; Rangell, 1951) but lacked the methodology and psychometric tools necessary to establish a relationship between adverse emotional experiences of individuals and the occurrence of heart disease, particularly coronary heart disease (CHD). Advances in psychology and the development of new comprehensive models for the impact of emotions on health outcomes have facilitated research of this unexplored area on the interface between psychology and medicine (Gallo, Ghaed, \& Bracken, 2004).

Thus far there is a growing body of evidence linking CHD to mental diseases such as overt anxiety and depression (Day, Freedland, \& Carney, 2005; Denollet, Strik, Lousberg, \& Honig, 2006; Kubzansky, Cole, Kawachi, Vokonas, \& Sparrow, 2006; Panagiotakos, Pitsavos, Chrysohoou, Stefanadis, \& Toutouzas, 2002; Rugulies, 2002; Strik, Denollet, Lousberg, \& Honig, 2003).

Research on the cardiac aftereffects of suboptimal psychological states within the range of normal behavior has also been significant albeit less conclusive (Scheidt, 2000; Trichopoulos, Katsouyanni, Zavitsanos, Tzonou, \& Dalla-Vorgia, 1983; Zyzanski, Jenkins, Ryan, Flessas, \& Everist, 1976). Moreover, much attempt has been made for the evaluation of the impact of stress-related emotions and cognitions such as anger and hostility (Mittleman, Maclure, Sherwood, Mulry, Tofler, Jacobs, Friedman, Benson, \& Muller, 1995), certain personality 
types (Kawachi, Sparrow, Kubzansky, Spiro, Vokonas, \& Weiss,1998) and aspects of negative affectivity (Pitsavos, Panagiotakos, Lentzas, \& Stefanadis, 2005; Tennant \& McLean, 2001) on the incidence and clinical evolution of CHD.

Most pioneer efforts, however, have failed to use an operational model for measuring, interpreting, and conceptualizing potential emotional factors in CHD (Williams, Kiecolt-Glaser, Legato, Ornish, Powell, Syme, \& Williams, 1999). As a result, various vaguely defined constructs such as "emotional vitality" (Kubzansky \& Thurston, 2007), "emotional distress" (Lipp, Pereira, Justo, \& de Matos, 2006) and "negative emotions" (Smith, 2001; Gallo \& Mathews, 2003) have been employed by scientists in an effort to sketch the emotional orientation of CHD.

As indications towards the beneficial effects of psychosocial interventions in CHD patients accumulate (Linden, 2000), the need for a concise theory around the heart-mind/emotions relationships emerges stronger than ever. The present study is an attempt towards this end by examining whether the theoretical model of trait emotional intelligence (EI) can be efficient for the description of psychological determinants of heart disease.

Emotional intelligence (EI) is a relatively new construct in psychology. Its distal roots go back to the concept of "social intelligence" introduced by Thorndike (1920) and to the "non-intellective" elements of intelligence such as affective, personal and social factors developed by Wechsler (1940). Its proximal roots lie in work pertaining to psychotherapy treatments (Leuner, 1966), promotion of personal and social improvement (Beasley, 1987; Payne, 1986) and to the idea of multiple intelligences proposed by researchers like Gardner (1983) and Sternberg (1985).

Salovey and Mayer (1990) proposed the first theoretical model, which defined the construct of EI as a "subset of social intelligence that involves the ability to monitor one's own and others' feelings and emotions, to discriminate among them and to use this information to guide one's thinking and actions" (p. 189) (see also Mayer \& Salovey, 1997). A number of different definitions of the construct followed -including Goleman's account in his best-selling book (1995)-, which have failed to provide a universally accepted operational model of EI. Instead, they distinguish between two types of EI: trait (or trait emotional self-efficacy) EI and ability (or cognitive-emotional abilty) EI on the basis of the measures (self-report vs maximum performance questionnaires) used to assess EI (Petrides \& Furnham, 2001; Petrides, Frederickson, \& Furnham, 2004; Petrides, Pita, \& Kokkinaki, 2007). A content analysis performed by Petrides and Furnham on the salient operational definitions of EI (2001) revealed its 15 distinct components, namely: adaptability, assertiveness, emotion expression, emotion management, emotion perception, emotion regulation, impulsiveness, relationship skills, self-esteem, self-motivation, social competence, stress management, trait empathy, trait happiness and trait optimism (see also Petrides et al., 2004).

The studies focused on the implications of trait EI in the educational and occupational domains, which show that EI is positively related to academic performance and behavior at school (Author, 2004; Parker, Summerfeldt, Hogan, \& Majeski, 2004; Petrides et al., 2004; Reiff, Hatzes, Bramel, \& Gibbon, 2001; Mayer, Roberts, \& Barsade, 2008) and job performance and job satisfaction (Wong \& Law, 2002; see also Mayer et al., 2008) suggest that future research should focus on the implications of EI in clinical settings. The present study provides a step towards this direction by examining relationships between trait EI and cardiovascular health.

Focused on several components of trait EI such as emotion expression, emotion perception and emotion regulation, the study aims to examine whether the scores on psychometric tools for measuring trait EI are associated with occurrence of CHD in Greek urban population while taking into account already identified highly significant risk factors for the disease, namely, age, gender, cigarette smoking, presence of hypertension, obesity and family history of CHD (Panagiotakos, et al., 2002; O’Donnell \& Elosua, 2008). It was hypothesized that perceived ability to use, regulate and express emotions as well as frequent expression of positive emotions would be associated with decreased incidence of CHD.

\section{Research Methods}

\subsection{Design}

The study was conducted between July 1st, 2006 and October 30th, 2007 in the Athens Naval Hospital, following approval by the Institution's Committee on Human Research and Bioethics.

\subsection{Subjects}

All patients that were admitted in the Cardiology Department within the above period were considered for participation in the study. Their medical records were browsed on the day prior to discharge and those with angiographic evidence of coronary artery disease were included in the study as Cases. Patients with congenital 
heart disease, dementia and psychiatric conditions were excluded. Subsequent visits of the same patient were not taken into account. A total of 56 eligible patients with CHD who consented to participate in the study were included as Cases, comprising 43 men $(78.2 \%, 33-80$ years, median=67 years) and 13 women $(21.8 \%, 40-87$ years, median $=72$ years).

Potential controls were asked to provide the researchers with an ECG and a consultation note from a cardiologist dated within the previous six-month period indicating no signs of heart disease. The ones that presented such documentation were included in the study as Controls. There were 56 participants in the control arm, of which 36 were men $(52.4 \%, 21-70$ years, median $=54$ years $)$ and 20 were women $(47.6 \%, 19-51$ years, median=32 years).

\subsection{Measures}

Two researchers were randomly assigned to the participants and instructed them towards the completion of two separate self-report questionnaires: The Wong-Law Emotional Intelligence Scale and the Self-Expressiveness in the Family Questionnaire. Demographic and medical history data were recorded on standardized forms.

Wong-Law Emotional Intelligence Scale (WLEIS; Wong \& Law, 2002/Kafetsios \& Zampetakis, 2008).

The Greek version of the self-report Wong-Law Emotional Intelligence Scale (WLEIS) was used. WLEIS provides a good coverage of trait EI. It is also one of the few self-report scales that allow for distinguishing among EI dimensions. The Scale consists of 16 items, which form four dimensions. The "Self-emotion Appraisal" (SEA) dimension concerns a person's ability to understand his/her emotions. The "Others' Emotion Appraisal" (OEA) dimension assesses an individual's tendency to be able to perceive the emotions of other people, the "Use of Emotion" (UOE) dimension refers to the self-perceived tendency to motivate one self to enhance performance, and the "Regulation of Emotion" (ROE) dimension relates to an individual's perceived ability to regulate his/her own emotions. The internal consistency reliability (coefficient alpha) for the Greek version of the WLEIS is .90. For a list of the items fused to form the four dimensions see Table 1.

\section{Self-Expressiveness in the Family Questionnaire (SEFQ; Halberstadt et al., 1995)}

Self-Expressiveness in the Family Questionnaire is a self-report measure, which is designed to examine the frequency of an individual's emotional expressiveness within the family. The version used in this study has been adapted into Greek (Maridaki-Kassotaki, Tsitsas, Antonopoulou, \& Voutyra, in press). It consists of 40 statements, 23 statements describe concrete examples of positive expressiveness (e.g. "Expressing deep affection or love for someone," "Offering to do somebody a favor") while the other 17 statements describe negative expressiveness (e.g. "Showing contempt for another's actions," "Expressing momentary anger over a trivial irritation"). The SEFQ has received support for its psychometric properties including high internal consistency of its subscales, test-retest reliability and validity and reported Cronbach's alphas of .92 and .86 for the positive and negative subscales respectively (Halberstadt, 1986; Halberstadt, Cassidy, Stifter, Parke, \& Fox, 1995).

\subsection{Statistical Analysis}

Spearman's correlation coefficients were used in preliminary data analysis in order to identify correlations between independent variables. Differences in distributions of characteristics in Cases and Controls were assessed using Pearson's Chi-square and the Mann-Whitney-Wilcoxon statistic.

Logistic regression models (Hosmer, \& Lemeshow, 1989) were fitted in order to assess unifactorial and multifactorial correlations of CHD. Of the psychological factors under investigation, the ones that exhibited statistical significance (level set at 0.05 ) in the univariate model were subsequently evaluated within a multiple regression model. Well-established risk factors (age, gender, hypertension, family history for CHD, obesity and smoking) were forced to remain in the model regardless of statistical significance so as to provide an unbiased estimate of the effect of psychological determinants (Brenner \& Blettner, 1997; Hosmer \& Lemeshow, 1989). In the case of emotional expressiveness components, the likelihood ratio statistic was implemented to select the final model over the four possible fully adjusted models (positive emotional expression with or without negative emotional expression and with or without interaction term (Clayton \& Hills, 1998).

STATA version 9 (Statcorp., College Station, TX, USA) was used for all analyses.

\section{Results}

As presented in Table 2, age, male gender, hypertension, CHD in the family history, obesity, smoking, self-emotion appraisal (SEA), use of emotions (UOE), regulation of emotions (ROE) as well as frequency of negative expressiveness were all univariately significantly associated with greater odds of developing CHD. More analytically, the results pertaining to each of the two measures used in the study are as follows: 


\subsection{Wong-Law Emotional Intelligence Scale (WLEIS)}

In the univariate analysis, for each one of the ROE and UOE components of the Scale one unit increase in the relevant scores reflecting self-reported decreased ability to regulate and make use of one's emotions respectively is associated with two-fold increase in the odds for CHD. Appraisal of one's own emotions (SEA) was also significant at the 0.05 level thus showing increase in the odds of the disease by $50 \%$ for one unit increase in the relevant score. Appraisal of emotions of others did not appear to play a part in the occurrence of the disease since its effect failed to reach significance ( $p$-value $=0.114$ ).

In the second stage of the analysis, the effects of UOE and ROE components were not blunted by adjusting for age, gender, family history of CHD, hypertension, obesity and smoking thus demonstrating five-fold increase in the odds ratio for the disease for one unit increase in the scores for both components. The SEA score was not found to be statistically significant in the fully adjusted model.

\subsection{Self-Expressiveness in the Family Questionnaire (SEFQ)}

In the univariate analysis, increased frequency of negative expressiveness was associated with about three-fold odds of being affected by CHD. In the context of a multiple logistic regression model, an odds ratio of 15.40 (see Table 3) was estimated for the same effect. Increased frequency of positive expressiveness did not appear to alter the odds of the disease to a significant degree.

Further, there was no modification on the effect of frequency of negative expressiveness by frequent expression of positive emotions by the same individual as indicated by a p-value of 0.168 for the inclusion of an interaction term.

UOE, ROE, and frequency of negative expressiveness could not be included in the same model due to significant correlations between them, which gave rise to multicollinearity. Therefore, three distinct multiple regression models, one for each component, were fitted (Table 3). The results of the analysis indicated that UOE explained $69.92 \%$ of the disease variability. The corresponding percentages for ROE and frequency of negative expressiveness were $65.86 \%$ and $68.63 \%$ respectively.

\section{Discussion}

The purpose of this study was to examine relationships between trait emotional intelligence (EI) and coronary heart disease (CHD). Consistent with our hypotheses, components of trait EI such as perceived ability to use and regulate emotions in everyday life as well as frequency of expression of negative emotions were found to differ significantly among patients and non-patients. More specifically, patients with CHD seem to perceive themselves as less able to use and regulate their emotions than individuals without CHD. They also express negative emotions more frequently than those who do not have CHD. A possible explanation for the present results can be provided by the theory of emotion regulation proposed by Gross and John (2003). According to this theory, individuals who are good at using strategies to manage and regulate their emotions as to those who suppress their emotions by inhibiting ongoing emotion-experience behavior have greater levels of well-being in a number of factors reflecting good health such as life satisfaction, self-esteem, optimism, environmental mastery, autonomy, personal growth, purpose in life, self-acceptance, positive relations with others, mood, etc.

The reported findings come to add down to a growing list of bibliography striving to shed light on the mystery behind heart-mind relationships (Kubzansky \& Thurston, 2007; Kubzansky, Kawachi, Spiro, Weiss, Vokonas, \& Sparrow, 1997; Kubzansky \& Kawachi, 2000; Ong \& Allaire, 2005; Rozanski, Blumenthal, Davidson, Saab, \& Kubzansky, 2005; Scheidt, 2000; Smith \& Ruiz, 2002; Wittstein, 2007). They also support and expand the empirical basis of the EI construct and underlie its relevance in the clinical arena thus pointing to potentially fruitful applications that might be of interest to cardiologists.

Contrary to Frederickson and colleagues (Frederickson, Mancuso, Branigan, \& Tugade, 2000) as well as Ong and Allaire (2005), we did not find frequent expression of positive emotions to have "buffering" potential on the detrimental effects of negative emotions. The data of the present study indicate that the burden of bodily adaptations occurring when an individual is chronically exposed to negative emotional states cannot be undone by the potential opposite changes brought about by positive feelings either because these changes do not actually take place or because they are not extensive enough.

Thus far, a number of researchers have proposed the direct impact of psychosocial factors on CHD through physiological alterations innate to emotional experiences (Lovallo \& Gerin, 2003). An indirect association between psychosocial factors and CHD expressed by the claim that positive emotional orientation helps individuals maintain a healthier lifestyle has also been proposed by other researchers (Krantz \& McCeney, 2002). The present findings provide support for the direct impact of psychosocial factors on CHD versus the 
lifestyle-mediated one since they indicate that compounds of trait EI alter the odds for the disease above and beyond conventional risk factors. This conclusion is in accordance with the one derived from the INTERHEART study involving nearly 25,000 participants from 52 countries (Rosengren, Hawken, Ounpuu, Sliwa, Zubaid, Almahmeed, Blackett, Sitthi-amorn, Sato, \& Yusuf, 2004). Nevertheless, the fact that the estimates of odds ratios attributed to differences in psychological characteristics appear augmented in the presence of potential confounders could be due to a true confounding relationship between at least one of the conventional risk factors and emotional parameters (Clayton \& Hills, 1998).

It is worth mentioning that the link between acute and intense emotional experiences and cardiovascular events has long been described by epidemiologists (Trichopoulos, et al., 1983). The usual claim is that when individuals are incapable of using their emotions to achieve desired social functioning they are in a constant state of stress and unpleasant realization (Lipp, et al., 2006; Thurston \& Kubzansky, 2007). Thus, they might be continuously harming their cardiovascular system by the same mechanism that would occur on an acute event but on a much smaller scale. In other words, constant presence of tolerable emotional distress and impaired social functioning could render sub-clinical atherosclerosis clinically significant in the same way that a single episode of severe emotional stress might precipitate an acute coronary syndrome.

With respect to the above claim and on the basis of the present evidence, the effect of trait EI on CHD occurrence may be schematically presented as in Figure 1. As shown in the figure, decreased ability to use and regulate one's emotions as well as frequency of negative expressiveness, which reflect low trait EI, render the individual vulnerable to stressors present in socially demanding situations (Lipp et al., 2006). If an individual is unable to cope with socially demanding situations, he/she is exposed to adverse emotional states (Lopes, Brackett, Nezlek, Schütz, Sellin, \& Salovey, 2004; Mikolajczak, Luminet, \& Menil, 2006). Those untoward states can, in turn, cause maladaptive physiological changes (McEwen, 1998; Rozanski, Blumenthal, \& Kaplan, 1999) including cardiovascular reactivity (Lipp et al., 2006) neuroendocrine pathways, especially the pituitary-adrenal axis (McEwen \& Lasley, 2003; Linkowski, 2003; Pajer, 2007), autonomic nervous system mis-regulation and modification of the immune system (Appels et al., 2000). The above maladaptive physiological changes, which are also likey to be caused by the conventional risk factors of the CHD may be responsible for the onset of CHD.

In sum, the present study expands previous work by assessing CHD occurrence within the theoretical framework of emotional intelligence while taking into account all of the risk factors derived from the medical history. To our knowledge, it is also the first study examining the association of CHD and EI, and thus it emphasizes the need for further research on EI in the clinical domain. Such research will enable us not only to elucidate how trait EI is implicated in clinical settings, but also to understand better the emotional processes that are responsible for CHD.

\section{References}

Appels, A., Bär, F. W., Bär, J., Bruggeman, C., \& de Baets, M. (2000). Inflammation, depressive symptomatology, and coronary artery disease. Psychosomatic Medicine, 62(5), 601-605.

Aschoff, L. (1933). Introduction. In E.V. Cowdry (Ed.), Atherosclerosis: A survey of the problem (pp. 1-18). McMillan: New York.

Beasley, K. (1987). The emotional quotient. The British Mensa Magazine, May, 25.

Bar-On, R. (1997). BarOn Emotional Quotient Inventory: Technical Manual. Toronto: Multi-Health Systems.

Boshes, B. (1958). Emotions, hypothalamus and the cardiovascular system. American Journal of Cardiology, $1(2), 212-223$.

Brenner, H. \& Blettner, M. (1997). Controlling for continuous confounders in epidemiologic research. Epidemiology, 8(4), 429-434.

Cerný, M., Dolezalová, V., Pokorná, P., \& Jirák, R. (1975). Cardiovascular reactions to physical exertion, psychogenic stress and to hypnotically induced emotions. Activitas Nervosa Superior (Praha), 17(1), 38-39.

Clayton, D. \& Hills, M. (1998). Statistical models in epidemiology. Oxford: Oxford University Press.

Day, R.C., Freedland, K.E., \& Carney, R.M. (2005). Effects of anxiety and depression on heart disease attributions. International Journal of Behavioral Medicine, 12(1), 24-29.

Denollet, J., Strik, J. J., Lousberg, R., \& Honig, A. (2006). Recognizing increased risk of depressive comorbidity after myocardial infarction: Looking for 4 symptoms of anxiety-depression. Psychotherapy and Psychosomatics, $75(6), 346-352$. 
Friedman, M., \& Rosenman, R.H. (1964). Emotions in Cardiovascular Disease. The Heart Bulletin, 13, $21-23$.

Frederickson, B. L., Mancuso, R. A., Branigan, C., \& Tugade, M. M. (2000). The undoing effect of positive emotions. Motivation and Emotion, 24, 237-258.

Gallo, L.C., Ghaed, S.G., \& Bracken, W.S. (2004). Emotions and cognitions in coronary heart disease: Risk, resilience, and social context. Cognitive Therapy and Research, 28(5), 669-694.

Gallo, L.C., \& Matthews, K.A. (2003). Understanding the association between socioeconomic status and physical health: Do negative emotions play a role? Psychological Bulletin, 129(1), 10-51.

Gardner, H. (1983). Multiple Intelligences: The theory in practice. New York: Basic Books.

Goleman, D. (1995). Emotional Intelligence. New York: Bantam Book.

Gross, J., J. \& John, O.P. (2003). Individual differences in two emotion regulation processes: Implications for affect, relationships, and well-being. Journal of Personality and Social Psychology, 85(2), 348-362.

Halberstadt, A.G. (1986). Family socialization of emotion expression and nonverbal communication styles and skills. Journal of Personality and Social Psychology, 51, 827-836.

Halberstadt, A. G., Cassidy, J., Stifter, C. A., Parke, R. D., \& Fox, N. A. (1995). Self expressiveness within the family context: Psychometric support for a new measure. Psychological Assessment, 7, 93-103.

Harris, C.R.S. (1973). The heart and vascular system in ancient Greek medicine from Alkmaeon to Galen. Oxford: Clarendon Press

Hosmer, D.W., \& Lemeshow, S. (1989). Applied logistic regression. New York: Wiley Interscience.

Kafetsios, K., \& Zampetakis, L. (2008). Emotional Intelligence and job satisfaction: Testing the mediatory role of positive and negative affect at work. Personality and Individual Differences, 44, 710-720.

Kawachi, I., Sparrow, D., Kubzansky, L. D., Spiro, A. 3rd, Vokonas, P. S., \& Weiss, S. T. (1998). Prospective study of a self-report type A scale and risk of coronary heart disease: Test of the MMPI-2 type A scale. Circulation, 98(5), 405-12.

Krantz, D.S., \& McCeney, M.K. (2002). Effects of psychological and social factors on organic disease: a critical assessment of research on coronary heart disease. Annual Review of Psychology, 53, 341-69.

Kubzansky, L. D., Kawachi, I., Spiro, A 3rd, Weiss, S. T., Vokonas, P. S., \& Sparrow, D. (1997). Is worrying bad for your heart? A prospective study of worry and coronary heart disease in the Normative Aging Study. Circulation, 95(4), 818-24.

Kubzansky, L.D., \& Kawachi, I. (2000). Going to the heart of the matter: Do negative emotions cause coronary heart disease? Journal of Psychosomatic Research, 48(4-5), 323-37.

Kubzansky, L. D., Cole, S. R., Kawachi, I., Vokonas, P., \& Sparrow, D. (2006). Shared and unique contributions of anger, anxiety, and depression to coronary heart disease: A prospective study in the normative aging study. Annals of Behavioral Medicine, 31(1), 21-9.

Kubzansky, L.D., \& Thurston, R.C. (2007). Emotional vitality and incident coronary heart disease: Benefits of healthy psychological functioning. Archives of General Psychiatry, 64(12), 1393-401.

Lovallo, W.R., \& Gerin, W. (2003). Psychophysiological reactivity: Mechanisms and pathways to cardiovascular disease. Psychosomatic Medicine, 65(1), 36-45.

Leuner, B. (1966). Emotional intelligence and emancipation. Praxis der Kinderpsychologie und Kinderpsychiatrie, 15, 193-203.

Lewis, S. (2005). Broken heart syndrome: Perspectives from East and West. Advances in Mind-Body Medicine, 21(2), 3-5.

Linden, W. (2000). Psychological treatments in cardiac rehabilitation: Review of rationales and outcomes. Journal of Psychosomatic Research, 48(4-5), 443-445.

Linkowski, P. (2003). Neuroendocrine profiles in mood disorders. International Journal of Neuropsychopharmacology, 6(2), 191-197.

Lipp, M. E., Pereira, M. M., Justo, A. P., \& de Matos, T. M. (2006). Cardiovascular reactivity in hypertensives: Differential effect of expressing and inhibiting emotions during moments of interpersonal stress. Spanish Journal of Psychology, 9(2), 154-161. 
Lopes, P. N., Brackett, M. A., Nezlek, J. B., Schütz, A., Sellin, I., \& Salovey, P. (2004). Emotional intelligence and social interaction. Personality and Social Psychology Bulletin, 30(8), 1018-1034.

Maridaki-Kassotaki, K., Tsitsas, G., Antonopoulou, K., \& Voutyra, A. (in press). The Greek version of the Self-Expressiveness in the Family Questionnaire. In A. Stalikas, P. Roussi, \& S. Triliva (Eds.), Psychometric tools in Greece, vol. II. Athens: Ellinika Grammata.

Maridaki-Kassotaki, K. (2004). Examining the relation between emotional intel-ligence, academic performance and self-esteem. Paper presented at the $1^{\text {st }}$ International Conference of the Psychological Society of Northern Greece, University of Thessaloniki, 8-5/12.

Mayer, J. D., Salovey, P., Caruso, D. R., \& Sitarenios, G. (2001). Emotional intelligence as a standard intelligence. Emotion, 1(3), 232-242.

Mayer, J.D., \& Salovey, P. (1997). What is emotional intelligence? In P. Salovey, \& D. J. Sluyter (Eds.), Emotional development and emotional intelligence: Educational implications (pp.3-31). New York: Basic Books.

Mayer, J.D., Roberts, R.D. \& Barsade, S.G. (2008). Human abilities: Emotional intelligence. Annual Review of Psychology, 59, 507-536.

McEwen, B., \& Lasley, E.N. (2003). Allostatic load: When protection gives way to damage. Advances in Mind-Body Medicine, 19(1), 28-33.

McEwen, B.S. (1998). Protective and damaging effects of stress mediators. The New England Journal of Medicine, 338(3), 171-179.

Mikolajczak, M., Luminet, O, \& C. Menil, C. (2006). Predicting resistance to stress: incremental validity of trait emotional intelligence over alexithymia and optimism. Psicothema, 18 Suppl, 79-88.

Mittleman, M. A., Maclure, M., Sherwood, J. B., Mulry, R. P., Tofler, G. H., Jacobs, S. C., Friedman, R., Benson, H., \& Muller, J. E. (1995). Triggering of acute myocardial infarction onset by episodes of anger. Determinants of myocardial infarction onset study investigators. Circulation, 92(7), 1720-1725.

Moodie, R.L. (1923). Paleopathology: An introduction to the study of ancient evidences of disease. Urbana: University of Illinois Press.

O'Donnell, C.J., \&. Elosua, R. (2008). Cardiovascular risk factors. Insights from Framingham Heart Study. Revista Spañola de Cardiología, 61(3), 299-310.

Ong, A.D., \& Allaire. (2005). Cardiovascular intraindividual variability in later life: the influence of social connectedness and positive emotions. Psychology of Aging, 20(3), 476-485.

Pajer, K.A. (2007). Cardiovascular disease risk factors in adolescents: do negative emotions and hypothalamic-pituitary-adrenal axis function play a role? Current Opinion in Pediatrics, 19(5), 559-564.

Panagiotakos, D. B., Pitsavos, C., Chrysohoou, C., Stefanadis, C., \& Toutouzas, P. (2002). Risk stratification of coronary heart disease in Greece: final results from the CARDIO2000 Epidemiological Study. Preventive Medicine, 35(6), 548-556.

Parker, D. A., Summerfeldt, L.J., Hogan, M.J., \& Majeski, S. A. (2004). Emotional intelligence and academic success: Examining the transition from high school to university. Personality and Individual Differences, 36, 163-172.

Parry, C.H. (1799). An inquiry into the symptoms and causes of the syncope anginosa commonly called angina pectoris. Bath: Curtwell, R.

Payne, W.L. (1986). A study of emotion: Developing emotional intelligence; Self-integration; relating to fear, pain and desire. Dissertation Abstracts International, 47, (01), p. 203A. (University Microfilms No. AAC 8605928).

Petrides, K.V., \& Furnham, A. (2001). Trait emotional intelligence: psychometric investigation with reference to established trait taxonomies. European Journal of Personality, 15, 425-448.

Petrides K.V., Frederickson N., \& Furnham, A. (2004). The role of trait emotional intelligence in academic performance and deviant behavior at school. Personality and Individual Differences, 36, 277-293.

Petrides, K.V., Pita, R. \& Kokkinaki, F. (2007). The location of trait emotional intelligence in personality factor space. British Journal of Psychology, 98, 273-289. 
Pitsavos, C., Panagiotakos, D. B., Lentzas, Y., \& Stefanadis, C. (2005). Epidemiology of leisure-time physical activity in socio-demographic, lifestyle and psychological characteristics of men and women in Greece: the ATTICA Study. BMC Public Health, 5(1), 37.

Rangell, L. (1951). The role of emotions in cardiovascular disorders. Annals of Western Medicine and Surgery, 5(7), 610-618.

Reiff, H.B., Hatzes, N. M., Bramel, M.H., \& Gibbon, T. (2001). The relation of LD and gender with emotional intelligence in college students. Journal of Learning Disabilities, 34, 66-78.

Rozanski, A., Blumenthal, J.A., \& Kaplan, J. (1999). Impact of psychological factors on the pathogenesis of cardiovascular disease and implications for therapy. Circulation, 99(16), 2192-217.

Rozanski, A., Blumenthal, J. A., Davidson, K. W., Saab, P. G., \& Kubzansky, L. (2005). The epidemiology, pathophysiology, and management of psychosocial risk factors in cardiac practice: The emerging field of behavioral cardiology. Journal of the American College of Cardiology, 45(5), 637-651.

Rosengren, A., Hawken, S., Ôunpuu S, Sliwa, K., Zubaid, M., Almahmeed, W. A., Blackett, K. N., Sitthi-amorn, C., Sato, H., \& Yusuf, S.; INTERHEART investigators. (2004). Association of psychosocial risk factors with risk of acute myocardial infarction in 11,119 cases and 13,648 controls from 52 countries (the INTERHEART study): Case-control study. Lancet, 364(9437), 953-962.

Rugulies, R. (2002). Depression as a predictor for coronary heart disease. A review and meta-analysis. American Journal of Preventive Medicine, 23(1), 51-61.

Salovey, P., \& Mayer, J.D. (1990). Emotional intelligence. Imagination, Cognition and Personality, 9(3), 185-211.

Sandison, A.T. (1967). Degenerative vascular disease. In D., Brothwel, \& A. T. Sandison (Eds.), Diseases in antiquity: A survey of diseases, injuries and surgery of early populations (pp.474-488). Springfield: Charles C. Thomas.

Scheidt, S. (2000). The current status of heart-mind relationships. Journal of Psychosomatic Research, 48(4-5), 317-320.

Smith, T.W., \& Ruiz, J.M. (2002). Psychosocial influences on the development and course of coronary heart disease: Current status and implications for research and practice. Journal of Consulting and Clinical Psychology, 70(3), 548-568.

Smith, D.F. (2001). Negative emotions and coronary heart disease: Causally related or merely coexistent? A review. Scandinavian Journal of Psychology, 42(1), 7-69.

Sternberg, R.J. (1985). Human intelligence: The model is the message. Science, 230, 1111-1118.

Strik, J. J., Denollet, J., Lousberg, R., \& Honig, A. (2003). Comparing symptoms of depression and anxiety as predictors of cardiac events and increased health care consumption after myocardial infarction. Journal of the American College of Cardiology, 42(10), 1801-1807.

Tennant, C., \& McLean, L. (2001). The impact of emotions on coronary heart disease risk. Journal of Cardiovascular Risk, 8(3), 175-183.

Thorndike, E. (1920). Intelligence and its uses. Harper's Magazine, 140, 227-235.

Thurston, R.C., \& Kubzansky, L.D. (2007). Multiple sources of psychosocial disadvantage and risk of coronary heart disease. Psychosomatic Medicine, 69(8), 748-755.

Trichopoulos, D., Katsouyanni, K., Zavitsanos, X., Tzonou, A., \& Dalla-Vorgia, P. (1983). Psychological stress and fatal heart attack: The Athens (1981) earthquake natural experiment. Lancet, 1(8322), 441-444.

Wechsler, D. (1940). Nonintellective factos in general intelligence. Psychological Bulletin, 37, 444-445.

Williams, R., Kiecolt-Glaser, J., Legato, M. J., Ornish, D., Powell, L. H., Syme, S. L., \& Williams, V. (1999). The impact of emotions on cardiovascular health. The Journal of Gender-Specific Medicine, 2(5), 52-58.

Wittstein, I.S. (2007). The broken heart syndrome. Cleveland Clinic Journal of Medicine, 74 Suppl 1, 17-22.

Wong, C.S., \& Law, K.S. (2002). The effects of leader and follower emotional intelligence on performance and attitude. Leadership Quarterly, 13, 243-274.

Zyzanski, S. J., Jenkins, C. D., Ryan, T. J., Flessas, A., \& Everist, M. (1976). Psychological correlates of coronary angiographic findings.International Medicine, 136(11), 1234-1237. 
Table 1. Items of the WLEIS fused to determine the score for "Self -emotion Appraisal"(SEA), "Others' Emotion Appraisal"(OEA), "Use of Emotion"(UOE) and "Regulation of Emotion"(ROE).

Self-emotion Appraisal (SEA)

1. I have a good sense of why I have certain feelings most of the time

2. I have good understanding of my own emotions

3. I really understand what I feel

4. I always know whether or not I am happy

Others' Emotion Appraisal (OEA)

5. I always know my friends' emotions

6. I am a good observer of others' emotions

7. I am sensitive to the feelings and emotions of others

8. I have good understanding of the emotions of people around me Use of Emotions (UOE)

9. I always set goals for myself and then try my best to achieve them

10. I always tell myself I am a competent person

11. I am a self-motivated person

12. I would always encourage myself to try my best

Regulation of Emotions (ROE)

13. I am able to control my temper and handle difficulties rationally

14. I am quiet capable of controlling my emotions

15. I can always calm down quickly when I am very angry

16. I have good control of my own emotions 
Table 2. Logistic Regression Analyses: Univariate analysis for the effect of physiological and emotional risk factors on $\mathrm{CHD}$

\begin{tabular}{|c|c|c|c|c|}
\hline & Effect & Odds Ratio & $95 \%$ Confidence Interval & $p$ \\
\hline & Age & 1.08 & $1.05-1.13$ & 0.001 \\
\hline & Gender (male) & 3.26 & $1.35-7.86$ & 0.009 \\
\hline & Hypertension & 24.00 & $5.28-109.14$ & 0.001 \\
\hline & $\begin{array}{l}\text { CHD in the family } \\
\text { history }\end{array}$ & 11.77 & $4.09-33.90$ & 0.001 \\
\hline & Obesity & 33.48 & $7.42-151.02$ & 0.001 \\
\hline & Smoking & 4.53 & $1.87-10.97$ & 0.001 \\
\hline & SEA & 1.53 & $1.04-2.23$ & 0.028 \\
\hline & OEA & 1.44 & $0.92-2.28$ & 0.114 \\
\hline & UOE & 1.88 & $1.28-2.75$ & 0.001 \\
\hline & ROE & 2.18 & $1.42-3.36$ & 0.001 \\
\hline & $\begin{array}{l}\text { Frequency of } \\
\text { positive expressiveness }\end{array}$ & 0.69 & $0.23-2.07$ & 0.504 \\
\hline & $\begin{array}{l}\text { Frequency of } \\
\text { negative } \\
\text { expressiveness }\end{array}$ & 3.25 & $1.53-6.91$ & 0.002 \\
\hline \multicolumn{5}{|c|}{$\mathrm{CHD}=$ Coronary Heart Disease } \\
\hline \multicolumn{5}{|c|}{ SEA $=$ Self-emotion Appraisal } \\
\hline \multicolumn{5}{|c|}{ OEA = Others' Emotion Appraisal } \\
\hline $\mathrm{UOE}=\mathrm{Us}$ & of Emotions & & & \\
\hline $\mathrm{OE}=\mathrm{R}$ & lation of Emotions & & & \\
\hline
\end{tabular}

Table 3. Logistic Regression Analyses: Association of psychometric factors, including a) WLEIS scores for ability to use and regulate emotions and b) SEQF scores for frequency of negative expressiveness, with coronary heart disease after adjusting for potential confounders

\begin{tabular}{lllll}
\hline Model* $^{*}$ & Odds Ratio & $95 \%$ Confidence Interval & $P$ & PseudoR $^{2}$ \\
\hline$\underline{\text { WLEIS }}$ & 4.99 & $1.59-15.70$ & 0.006 & $69.62 \%$ \\
UOE & 5.54 & $1.50-20.47$ & 0.010 & $65.86 \%$ \\
ROE & 15.40 & $2.22-106.92$ & 0.006 & $68.63 \%$ \\
\hline SEFQ & & & \\
Frequency of & & & \\
negative & & & \\
expressiveness & & & \\
\hline
\end{tabular}

*Age, gender, hypertension, CHD family history, obesity and cigarette smoking have been included in all models to adjust for potential confounding effect

Likelihood ratio tests for overall significance (versus null model): $\mathrm{p}<0.001$ for all models

WLEIS $=$ Wong-Law Emotional Intelligence Scale

$\mathrm{SEFQ}=$ Self -expressiveness in the Family Questionnaire

$\mathrm{UOE}=$ Use of Emotions

ROE $=$ Regulation of Emotions 
- Decreased ability to regulate and use one's emotions

- Frequency of negative

expressiveness

(= low trait EI)

Conventional modifiable risk factors:

- Nutrition

- Hyperlipidemia

- Diabetes Mellitus

- Obesity

- Exercise

- Hypertension

- Cigarette smoking

- Alcohol abuse demanding situations

- Frequent exposure to adverse emotional states

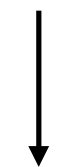

- Maladaptive physiological

changes:

- Cardiovascular reactivity

- Pituitary-adrenal axis

- Autonomic nervous system mis-regulation

- Immune system

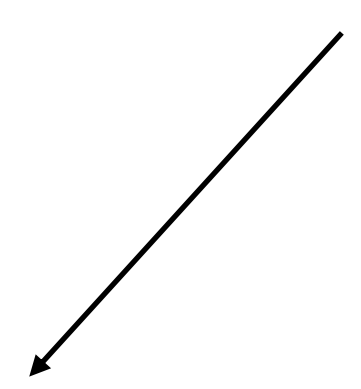

Coronary Heart Disease

Figure 1. Schematic representation of the effects of emotional intelligence (EI) components on coronary heart disease (CHD) 